\title{
Frequency of Low Back Pain and Other Associated Musculosk- eletal Disorders In City Bus Conductors of Guwahati city, Assam, India
}

\section{Surajit Roy ${ }^{1}$, Ujwal Bhattacharya *2, Kritica Boruah ${ }^{3}$, Urvashi Bhattacharya ${ }^{4}$.}

${ }^{1}$ Post Graduate Research Scholar, College of Physiotherapy and Medical Sciences, Guwahati , Assam, India.

*2 Professor cum Dean, Pratiksha Institute of Allied Health Sciences, Guwahati, Assam, India.

${ }^{3}$ Physiotherapist, NHM, Chera Talo District Hospital, Koloriang, Arunachal Pradesh, India.

${ }^{4}$ Assistant Professor, Department of Physiotherapy, University of Science and Technology Meghalaya, Meghalaya, India.

\section{ABSTRACT}

Background: Work-related musculoskeletal discomfort, especially low back pain (LBP) leads to substantial economic loss to individuals as well as to the community. Musculoskeletal disorders not only lead to loss of health but also loss of wealth. Bus conductors who are an important population in the community are at an increased risk of developing musculoskeletal symptoms. Their jobs involve prolonged standing and walking inside the bus for whole day which have been identified as risk factors for musculoskeletal discomfort.

Materials and methods: A survey of 100 bus conductors from different bus routes between the age group of 20 to 50 years, having at least 1-year working history and standing for 5 h/day, was conducted in Guwahati city of Assam state. Those with a history of trauma, preexisting medical conditions, or musculoskeletal deformities were excluded. Prevalence of LBP was assessed using Oswestry disability low back Pain Questionnaire, musculoskeletal discomfort was assessed by using Cornell musculoskeletal discomfort questionnaire. Mean, standard deviation and percentage was calculated for analysis.

Result: The mean for Oswestry disability low back pain score is 23.26 and SD is \pm 9.8786 . According to Oswestry disability LBP interpretation score it falls under 21- 40 percent- moderate disability. CMDQ scoring shows the mean SD is higher in lower back, neck and both the knees. The result of the study shows that bus conductors have a higher susceptibility to the back, neck and knees.

Conclusion: The bus conductors work continuously for long periods and their severe workload results in the development of disability in lower back. The conductors suffer from MSD in different parts of their body, particularly the lower back, neck and both knees, regions which hinders their normal work activities. Thus, it can be concluded that the bus conductors are highly stressed in their occupation due to the hazardous working condition and work behaviour, which also affects their health and overall work performance.

KEY WORDS: Low back pain, Musculoskeletal disorder, Work related musculoskeletal disorder, Bus conductors, Oswestry disability low back pain questionnaire, Cornell musculoskeletal discomfort questionnaire.

Address for correspondence: Dr. Ujwal Bhattacharya, PT., PhD, Professor cum Dean, Pratiksha Institute of Allied Health Sciences, Guwahati, Assam, India. E-Mail: ujwalbhatta@gmail.com
Access this Article online
Journal Information

Quick Response code

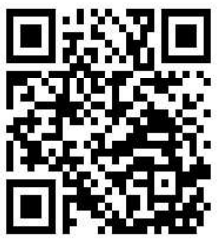

DOI: $10.16965 /$ ijpr.2021.134

\section{International Journal of Physiotherapy and Research}

ISSN (E) 2321-1822 | ISSN (P) 2321-8975 https://www.ijmhr.org/ijpr.html

DOI-Prefix: https://dx.doi.org/10.16965/ijpr

\section{Article Information}

Received: 04 May 2021

Peer Review: 05 May 2021

Revised: 22 May 2021
Accepted: 11 Jun 2021

Published (O): 11 Jul 2021

Published (P): 11 Aug 2021
INTRODUCTION

Backache is a vague terminology commonly understood as pain in back or in the region of spine [1]. Unfortunately it is often neglected 
as at individual as well at community level; mainly because of its non-fatal and benign nature. This is the reason why people as well as physicians tend to neglect it. But this problem has a huge impact on quality of life of the individuals. Chronic back pain if neglected may lead to disability or other severe medical conditions [2].

Backache or back pain is classified commonly based on anatomical site or based on aetiology. Anatomical classification is based on in which region pain exists i.e. cervical, thoracic, lumbar, and sacro-coccygeal. Usually lumbar and sacro-coccygeal area is considered as lower part of back and hence pain in this area is called as low back pain (LBP). Hence more emphasis has been given on low back pain (LBP) in this study [2,3].

Musculoskeletal discomfort is defined as a musculoskeletal injury that results from a work related event. Musculoskeletal discomfort affect the bones, muscle tendons, ligament, and nerves. It can be acute or chronic. It can be localised or widespread. Cause of MSD is trauma to an area, postural strain, repetitive movement, overuse, prolonged immobilization [4].

Work-related musculoskeletal disorders (WMSDs), are a common cause of work-related disability among workers with substantial financial consequences, due to workers' compensation and medical expenses $[5,6]$.

World Health Organization has defined a work-related disorder as one that results from a number of factors, and where the work environment and the performance of the work contribute significantly, but in varying magnitude, to the causation of the disease. MSDs represent a leading cause of occupational injury and disability in the developed and industrially developing countries such as India [5].

This may result in lost work time, work restriction, or transfer to another job.

Transport or transportation is the movement of people and goods from one place to another. The buses are staffed by two conductors and a driver. The conductors operate at the front and rear doors of the bus.
They run throughout the city on various routes. Consequently, many people work as conductors [5].

The regular work schedule of these conductors is alarming. They work continuously up to $16-18 \mathrm{~h}$ each day and there is no system of weekly time off for them. They work as long as their body permits and the duration may vary from 15 to 20 days at a stretch followed by a break of 4-5 days. They begin their work in early morning and end almost at midnight. They undertake 5-6 trips each day, where one trip means a to and fro journey, i.e., starting at the depot, going to the final destination and returning to the depot. The conductors do not work at a fixed door. They alternate at both doors of the bus. Moreover, the bus conductors perform a number of tasks when they are on duty $[5,7]$.

Work related problems are a common occupational hazard for bus conductors. Symptoms vary from person to person, but the common symptoms are pain, fatigue and sleep disturbances [4, 8].

Bus conductors are at an increased risk of developing musculoskeletal symptoms because they are exposed to various physical and psychological factors. Among these, low back pain (LBP) is most extensively reported. Their jobs involve prolonged standing and which have been previously identified as risk factors for musculoskeletal symptoms. Thus, they inevitably encounter various physical and psychological problems [5].

Among the different types of public transport city buses are most commonly used in Guwahati. There are no studies done on bus conductors of Guwahati. The study, therefore, aimed to determine the prevalence of LBP in bus conductors in Guwahati and its association with other musculoskeletal disorders. It is necessary for rational decisions concerning the development of effective preventive measures, where ergonomics can play a very big role $[5,9,10]$.

Somnath Gangopadhyay et al 2015 in an ergonomic study used REBA questionnaires to study the Prevalence of Musculoskeletal Disorders Among Indian Bus Conductors [5]. 
Kristjan Jansenet et al 2015 used the Cornell musculoskeletal discomfort questionnaire (CMDQ) to assess the musculoskeletal discomfort in production assembly workers [11].

CMDQ addresses severity and working ability interference effects of MS discomfort across 20 body parts $[11,12]$.

Many studies have been conducted regarding back pain and other musculoskeletal disorders among bus drivers in India, but there is rarely a study done among bus conductors of Assam. Also no studies have been done for back pain and other musculoskeletal disorders experienced by bus conductors in Guwahati, Assam.

\section{OBJECTIVE OF THE STUDY}

1. To find out the prevalence of low back pain among bus conductors in Guwahati, Assam and other associated musculoskeletal discomfort in various upper and lower body areas.

2. To find out which areas of the body are affected the most.

\section{METHODOLOGY}

This is a Survey study done among all the bus conductors plying at different routes of Guwahati city. The study involves total 100 subjects taken in a simple randomized manner for a duration of 3 months. Only the subjects fulfilling the inclusion criteria were included in the study. An informed consent was received from the subject before inclusion to the study. In order to measure the outcome of the study 2 tools were included The Oswestry Disability Index or Oswestry Low Back Pain Disability Questionnaire to find out the prevalence of low back pain and Cornell MS Discomfort Questionnaire (CMDQ ) to find out the musculoskeletal discomfort. The questionnaires were explained to them.

Statistical analysis was done by using mean and standard deviation. Mean and standard deviation is calculated from Oswestry Disability Low back pain questionnaire and Cornell Musculoskeletal Discomfort Questionnaires to find out the musculoskeletal discomfort like neck, shoulder, other areas of upper body and lower body, which all areas are affected mostly due their constant standing working posture.
Also calculate the percentage of bus conductors affected by various musculoskeletal discomfort and comparison between them.

\section{RESULT}

Table 1: Shows the mean and standard deviation for Oswestry disability low back pain score, the mean value is 23.26 and SD is \pm 9.8786 . According to Oswestry disability LBP interpretation score it falls under 21- 40 percent- moderate disability.

\begin{tabular}{cc}
\hline Mean & 23.26 \\
\hline SD & 9.878678 \\
\hline
\end{tabular}

Questionnaire description: 10 sections describing the pain and its impact, Each section scored from 0 to 5 with higher values indicating more severe impact. The value of all the 10 section is added and the percentage is calculated, for all the 100 subject separately. The formula that have used -total scored / 50 (total possible score) $\times 100$

Table 2: Percentage Of MSD In Different Parts Of Body.

\begin{tabular}{cc}
\hline Range & Counting \\
\hline $\mathbf{0 - 1 0}$ & 12 \\
$\mathbf{1 0 - 2 0}$ & 24 \\
$\mathbf{2 0 - 3 0}$ & 45 \\
$\mathbf{3 0 - 4 0}$ & 13 \\
$\mathbf{4 0 - 5 0}$ & 6 \\
\hline
\end{tabular}

Table 3: Cornell Musculoskeletal Discomfort Questionnaire Scoring.

\begin{tabular}{ll}
\hline \multicolumn{1}{c}{ Area of body } & $\begin{array}{c}\text { Percentage of subject } \\
\text { MSD }\end{array}$ \\
\hline Neck & $70 \%$ \\
\hline Rt shoulder & $42 \%$ \\
\hline Lt shoulder & $45 \%$ \\
\hline Upper back & $25 \%$ \\
\hline Rt upper arm & $26 \%$ \\
\hline Lt upper arm & $36 \%$ \\
\hline Lowe back & $98 \%$ \\
\hline Rt forearm & $30 \%$ \\
\hline Lt forearm & $29 \%$ \\
\hline Rt wrist & $33 \%$ \\
\hline Left wrist & $31 \%$ \\
\hline Hip & $43 \%$ \\
\hline Rt thigh & $30 \%$ \\
\hline Lt thigh & $29 \%$ \\
\hline Rt knee & $70 \%$ \\
\hline Lt knee & $71 \%$ \\
\hline Right lower leg & $33 \%$ \\
\hline Lt lower leg & $46 \%$ \\
\hline Rt foot & $33 \%$ \\
\hline Lt foot & $30 \%$ \\
\hline
\end{tabular}




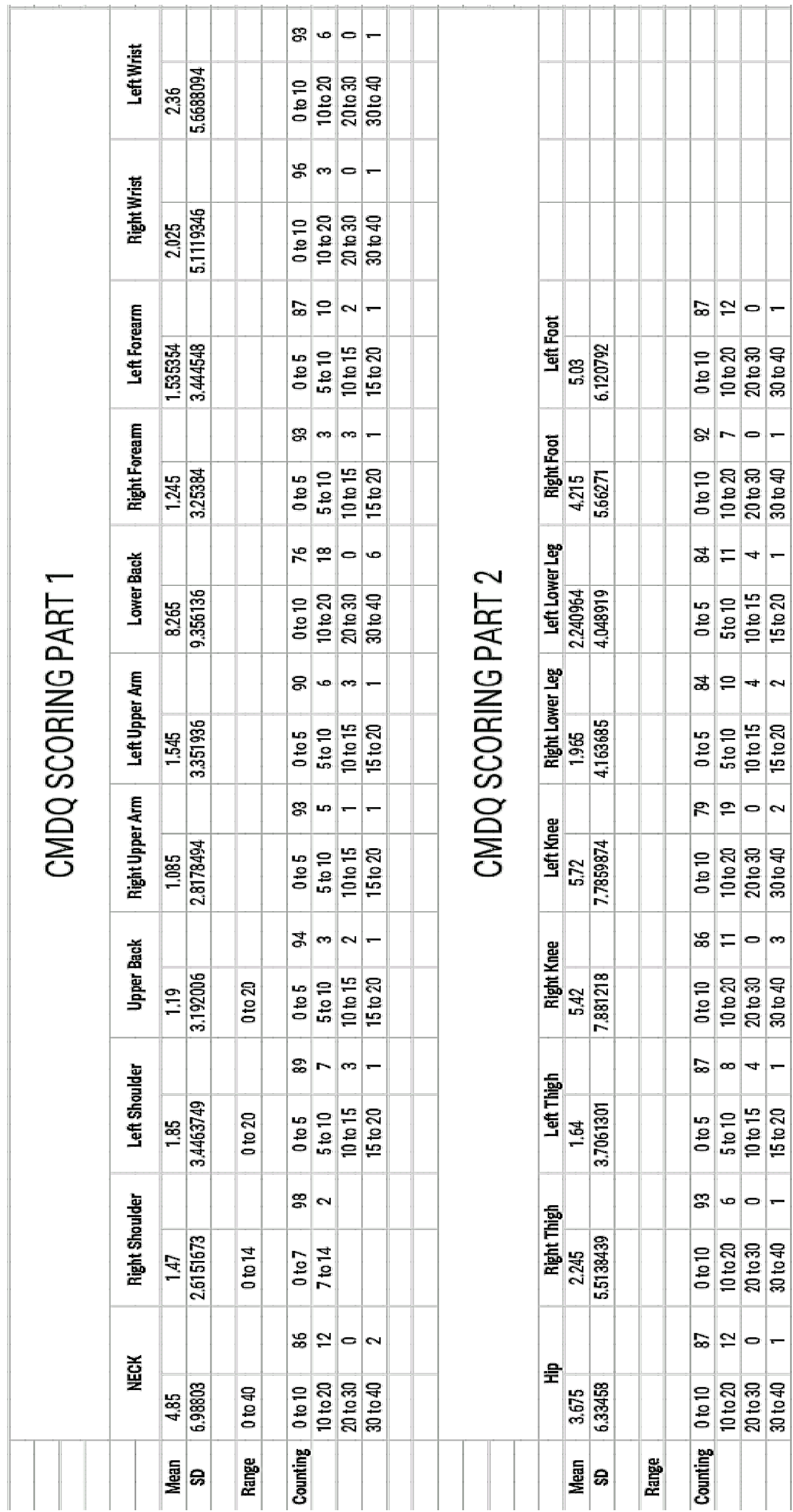


Graphical representation for Oswestry disability low back pain score mean value

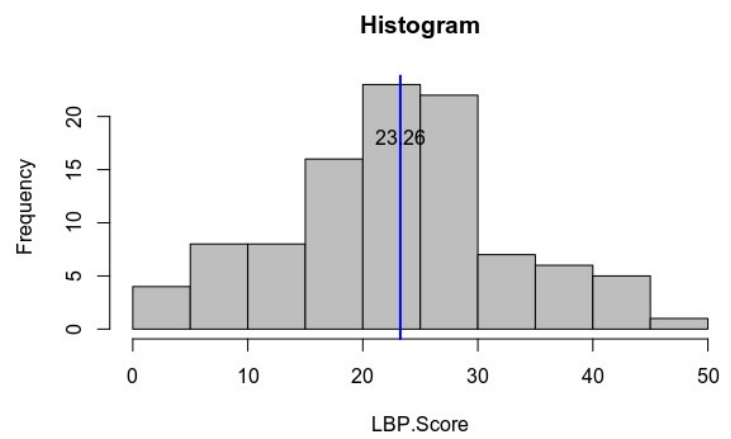

Fig. 1: Above histogram shows the Mean value of Low back pain . X-axis gives the range of score of LBP percentage and the $Y$ - axis gives the number of persons in that range.

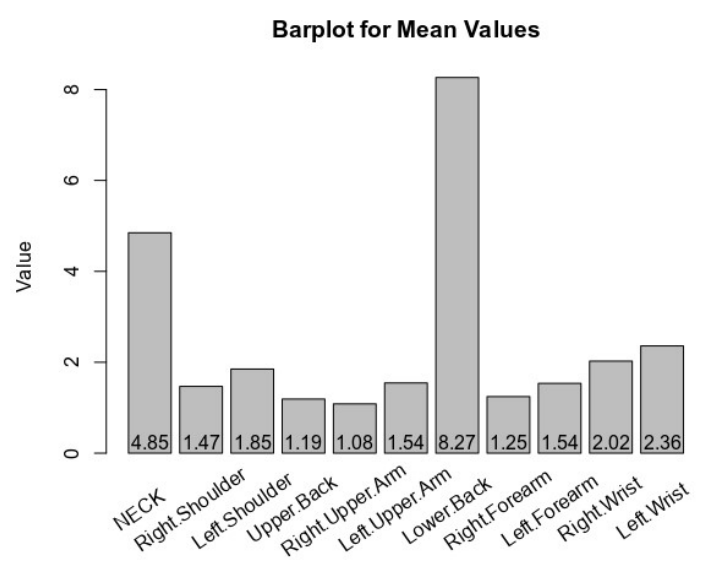

Fig. 2: Graphical representation of Mean values of CMDQ scoring Part 1.

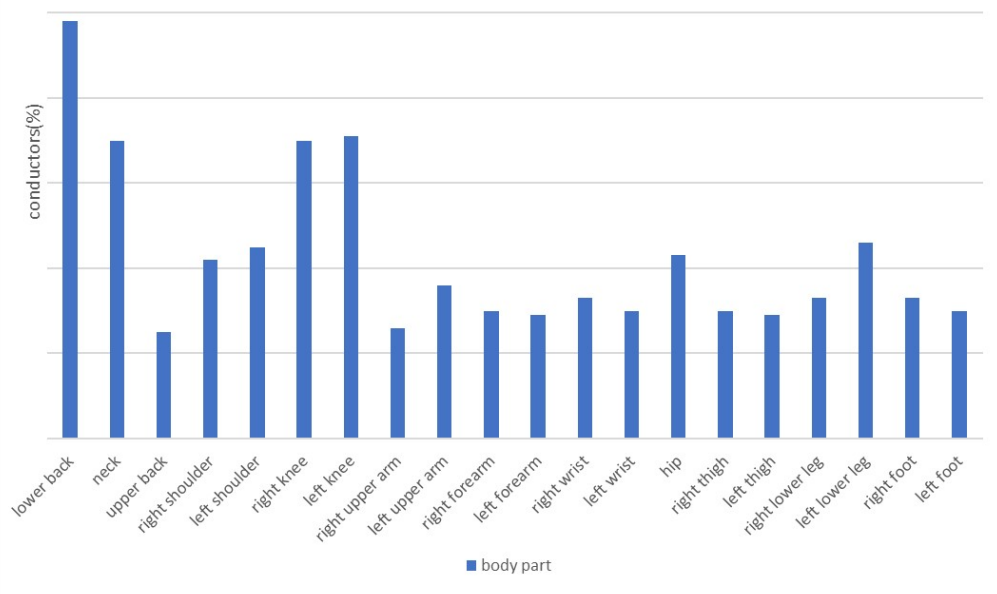

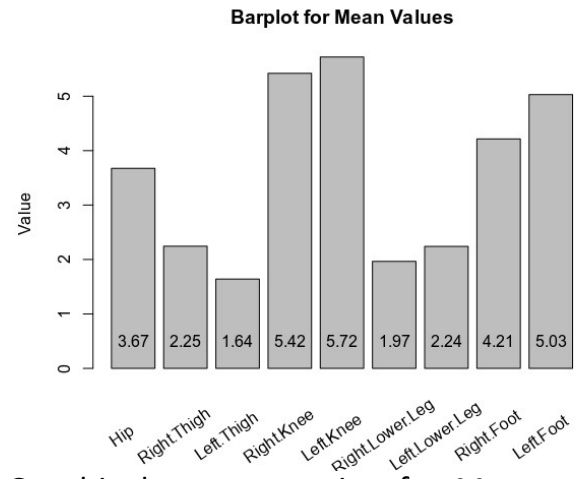

Fig. 3: Graphical representation for Mean values of CMDQ scoring Part 2.

Barplot for Standard Deviations

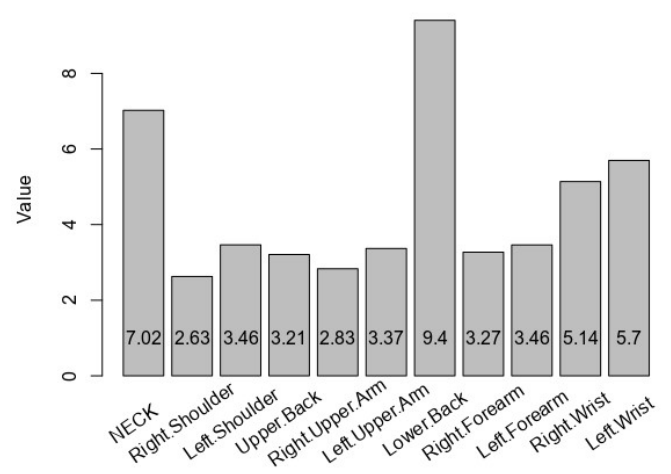

Fig. 4: Graphical representation for Standard Deviations of CMDQ scoring Part 1

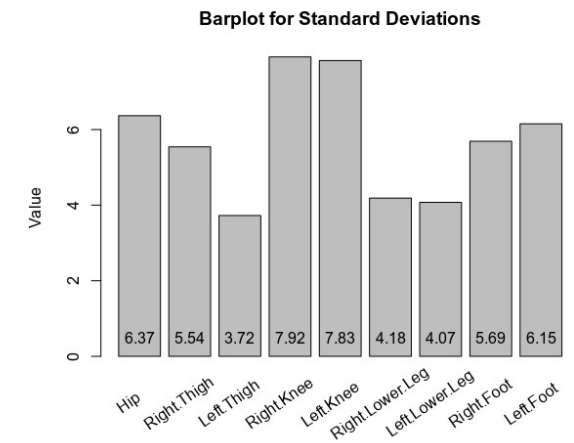

Fig. 5: Graphical representation of Standard Deviations of CMDQ scoring Part 2.

\section{Graphical representation of discomfort among bus conductors affecting different body parts in percentage}

Fig. 6: Discomfort among bus conductors affecting different body parts. 
Table 3 Shows the mean and standard deviation for CMDQ scoring comprising of maximum involvement in low back with $98 \%$ have musculoskeletal discomfort on lower back, the mean value is $8.26, S D \pm 9.35$. It is followed by involvement of knees and neck comprising of $71 \%$ have musculoskeletal discomfort on left knee, mean value 5.72 and SD is $\pm 7.78,70 \%$ have musculoskeletal discomfort on right knee, the mean value is 5.42 and SD is \pm 7.88 and $70 \%$ have musculoskeletal discomfort on neck, the mean value is 4.85 , SD \pm 6.98 rest all parts have an average involvement of $20 \%$.

\section{DISCUSSION}

In India, a large number of bus conductors are working in large cities. The study, therefore, aimed to determine the prevalence of LBP and other musculoskeletal discomfort in bus conductor of Guwahati, Assam, India.

The study examined mean and SD and found that the bus conductors have minimum disability according to Oswestry disability low back pain questionnaire which means they experience more pain and difficulty in sitting, lifting and standing. Travel and social life are more difficult. Personal care, sexual activity and sleeping are not grossly affected and can usually be managed by conservative means.

Several studies have shown similar results to the present study. Roopa Kurbett et al 2018 had done a study on Occupational problems of women bus conductors and found that women bus conductors highly suffer from pain in the leg, ankle/foot knees, thigh, lower back and palm region [7].

Prolonged standing at work has been associated with number of potentially serious health outcomes, such as low backache, leg pain, cardiovascular problem etc. Postural stress is the most common cause of low back pain. Generally in standing and walking, the increased pressure on spine can make the lower back muscles go into spasm, leading to pain. Researcher have suggested that risk of low back pain increases due to excessive co-activation of muscles involved in postural stability during prolonged standing [8].

Due to constant standing posture for 8-12 hours, abnormal posture and also the jerking of the bus increased the pressure on the spine which can make the lower back muscles go into spasm, leading to pain and disability.

This study examined the bus conductors musculoskeletal discomfort in all body areas through Cornell musculoskeletal discomfort questionnaire scoring. The mean and SD was calculated and found that the mean value is higher in lower back,( 8.27) neck(4.85), right knee(5.42), left knee (5.72), right foot (4.21) and foot (5.03) .

As bus conductors are in constant standing position for whole day and due to the abnormal posture the pressure over the spine is increased leading to musculoskeletal discomfort on lower back. Also there is an increased risk of pain and fatigue of both the lower limb and increase pressure over joints, mainly both the knees and both the foot.

As bus conductors constantly need to speak with passenger for money collection and look after all the passengers they constantly need to move their neck full day and develop musculoskeletal discomfort whereas the discomfort in upper arm, both the forearm, both the wrist, hip, both the thigh and both the leg is comparatively less.

Area wise the bus conductors have higher prevalence of musculoskeletal discomfort on lower back $98 \%$, left knee $71 \%$, right knee $70 \%$, neck $70 \%$, left shoulder $45 \%$, right shoulder $42 \%$.

Shariat et al 2016 in a study on prevalence rate of musculoskeletal discomfort based on severity level among office workers found that prevalence of pain in the neck, lower back and shoulder have been reported to be higher in comparison with pain in other parts of body [13].

Somnath Gangopadhyay et al in 2015 studied the prevalence of musculoskeletal disorders among Indian bus conductors and found high prevalence rates of musculoskeletal discomfort in the leg, knee, shoulder, back and neck areas which may be related to occupational factors contributing to undue stress on the various body parts [5].

Based on the study it found that the bus 
conductors work continuously for long periods and their severe workload may result in the development of minimal disability in lower back.

Prevalence of low back pain is higher with musculoskeletal discomfort in neck, both the knees, both the shoulder in compare to other areas.

The conductors suffer from MSD in different parts of their body, particularly more in the lower back, neck and both knee regions.

Limitations: It is not known whether this actually represents the true characteristics of the larger population of bus conductors as a whole. It is possible that such a study may have attracted more of those who have problems rather than those who do not. Psychological factor may have impact on conductor's musculoskeletal health.

Future Recommendation: Study involving larger sample size can be done. Physiological parameters can be calculated.

\section{CONCLUSION}

Musculoskeletal discomfort occurs primarily due to constant standing, prolonged working hours and excessive job stress caused by performing multiple tasks at the time. The mean value from CMDQ scoring concluded that lower back is mostly affected, in addition to lower back, neck, both the knees and, both the foot have higher MSD where as other areas like upper arm, forearm, wrist, hip, upper back, thigh, lower leg have less MSD.

The conductors suffer from MSD in different parts of their body, particularly more in the lower back, neck and both knees, regions, which hinders their normal work activities. Thus, it can be concluded that the bus conductors are highly stressed in their occupation due to the hazardous working condition and work behaviour, which also affects their health and overall work performance.

\section{Conflicts of interest: None}

\section{REFERENCES}

[1]. William C. Shiel Jr. Low back pain: signs and symptoms. MedicineNet. 09 Oct, 2019.
[2]. Dr. Abhijeet V. Jadhav. Prevalence of backache among bus drivers and associated modifiable risk factors in Latur, Maharashtra, Trivandrum. Achutha Menon Centre for Health Science Studies, Sree Chitra Tirunal Institute for Medical Sciences and Technology. May, 2012. Working Paper No.14.

[3]. Voon, Lim Chia and Kaur, Sharanjit and Ling, Tan Chieu. Prevalence of low back pain and disability among university students: a cross sectional study. 2013. Final year thesis. http://eprints.utar.edu.my/ 1710/

[4]. P. Hima Bindu,Thiruppathi Arjunan . Work related musculoskeletal discomfort among physiotherapist. Int J Physiother. October 2014;1(4):200-204.

[5]. Somnath Gangopadhyay, Samrat Dev, Tamal Das, Goutam Ghoshal, Tarannum Ara . An Ergonomics Study on the Prevalence of Musculoskeletal Disorders among Indian Bus Conductors. Int J Occup Saf Ergon. 2012;18(4):521-30.

[6]. D. E. Gyi, J. M. Porter. Musculoskeletal problems and driving in police officers. Occup Med (Lond) 1998 Apr; 48(3):153-60.

[7]. Roopa Kurbett, Veena S Jadhav. A study on Occupational problems of women bus conductors. International Journal of Home Science. 2018; 4(2):283-287.

[8]. Mohd Nasrull Abdol Rahman, U Joo Hui , Reazul Haq Abdul Haq, Mohd Fahrul Hassan, Ahmad Mubarak Tajul Arifin, Muhamad Zaini Yunos, Sharifah Adzila. Musculoskeletal discomfort among workers in mould making manufacturing industry. ARPN Journal of Engineering and Applied Sciences. Aug 2015;10(15).

[9]. Alan mozes et al. Standing all day at work may take toll on health. MedicineNet, Health day reporter, July 2015.

[10]. DEROS BM, YUSOFF ARM, ISMAIL SJ, DARUIS DDI. Optimizing Workstation Design for Standing Work System in an Electronics Assembly Work. Iran J Public Health. 2016;45(Supple 1):17-24.

[11]. Kristjan Jansen, Matis Luik, Märt Reinvee, Viljo Viljasoo, Jaan Ereline, Helena Gapeyeva, Mati Pääsuke. Musculoskeletal discomfort in production assembly workers. Acta Kinesiologiae Universitatis Tartuensis. 2012;18:102-110.

[12]. A Hedge, S Morimoto, D McCrobie. Effect of keyboard tray geometry on upper body posture and comfort, Ergonomics. 1999;42(10):1333- 1349.

[13]. A. Shariat, Sh. Bahri Mohd Tamrin, M. Arumugam, M. Danaee, R. Ramasamy. Prevalence rate of musculoskeletal discomfort based on severity level among office workers. Acta Medica Bulgarica. 2016;XLIII(1):54-63.

How to cite this article: Surajit Roy, Ujwal Bhattacharya, Kritica Boruah, Urvashi Bhattacharya. Frequency Of Low Back Pain and Other Associated Musculoskeletal Disorders In City Bus Conductors of Guwahati city, Assam, India. Int J Physiother Res 2021;9(4):3876-3882. DOI: 10.16965/ijpr.2021.134 